\title{
Editorial
}

\section{INFORMATION SYSTEMS OUTSOURCING IN THEORY AND PRACTICE}

\author{
THEME EDITORS: Leslie P. Willcocks, Templeton College, Oxford, UK
} and Mary C. Lacity, University of Missouri, St Louis, USA

\section{Introduction}

During the 1980s, American Airlines, American Hospital Supply (now Baxter), Merrill Lynch, and McKesson provided the exemplars for the management of information technology (IT). These companies testified to the competitive advantage which can be achieved through the successful exploitation of IT. A host of competitive advantage frameworks sought to formalize and further legitimate the strategic potential of IT (Ives and Learmouth, 1984; McFarlan, 1984; Porter and Millar, 1985; Feeny and Ives, 1989). In 1989, Kodak outsourced its IT functions to IBM, Businessland and DEC (Brown and Eckerson, 1990; Applegate and Montealegre, 1991; Hovey, 1991). This event publicized an alternative exemplar for the management of IT (Loh and Venkatraman, 1992a). Kodak was the first visible Fortune 500 company to argue that IT was primarily a commodity best handled by expert vendors, rather than a coveted strategic asset. Even Max HopperAmerican Airline's symbolic figurehead of the strategic potential of IT - claimed in 1990 that the old models of competitive advantage no longer applied because IT is too easily replicated to create a sustainable competitive advantage (Hopper, 1990). Therefore senior executives should seek to minimize IT costs, perhaps by outsourcing to a third party vendor.

The new examplars for IT management include British Petroleum, British Aerospace, Continental Bank, Continental Airlines, First Fidelity Bank, General Dynamics, the UK Inland Revenue, McDonnell Douglas, National Car Rental and Xerox (Harrar, 1993; Huber, 1993; Moad, 1993; Ganz, 1994; Melymuka, 1994). As more companies and public sector organizations jump on the outsourcing bandwagon, practitioners are gaining ample experiences of outsourcing 'successes' that lead to, for example, lower IT costs, increased service levels and more flexible IT management, as well as outsourcing 'failures' that lead perhaps to increasing IT costs, decreased service levels and/or inflexibility (see Lacity and Hirschheim (1993, 1995) and Willcocks and Fitzgerald (1994) for documented cases of outsourcing successes and failures). Enough evidence is now being accumulated to analyse and assess the practice through several theoretical perspectives. One possibility may be the eventual adoption of one common powerful theoretical perspective on outsourcing. Through this, academics and practitioners could well come to share a language to explain factors associated with successful and unsuccessful outsourcing experiences and so be able to provide guidelines for practice.

It is clear however that we are some way from such an outcome. In practice, as the outsourcing market grows for third party management of IT assets and services estimated in the USA at US $\$ 49.5$ billion revenues in 1994 - so information systems outsourcing is increasingly becoming the subject of considerable debate amongst academics and practitioners alike. In this theme issue we seek to contribute to this debate by collecting together a range of new papers that together represent a significant advance in both theoretical and empirical work. Throughout we define IS outsourcing broadly as the handing over to third party management of IT/IS assets, resources and activities for required result. The definition in the Clark et al. paper complements this where they describe outsourcing as the delegation, through a contractual arrangement, of all or any part of the technical resources, the human resources and the management responsibilities associated with providing IT services to an external vendor.

\section{Transaction cost theory}

One vital debate now is the degree to which various theoretical perspectives are more or less useful in explaining outsourcing outcomes and providing guidelines for practice. A dominant perspective found in the literature has been that of Transaction Cost Theory (TCT) as propounded by Williamson (1975, 1979, 1985). Several academics, such as Beath (1987), Klepper (1993), Lacity and Hirschheim (1993), and to a limited extent Bensaou (1993) and McFarlan and Nolan (1995), have proposed that TCT provides one theoretical framework for describing and explaining the IS outsourcing phenomenon. Our own research found a significant number of residuals (experiences not explained by TCT) and anomalies (experiences that 
contradict TCT) that challenged the applicability of TCT to the IS outsourcing context (Lacity and Willcocks, 1995). We found that residuals and anomalies existed because the nature of IT and IS outsourcing decisions tend to violate many TCT assumptions. We noted, however, that TCT proponents could explain the residuals and anomalies by appealing to TCT exceptions, such as uncertainty and small number of suppliers, or to ambiguities in TCT language. We also noted what Hodgson (1994) described as the 'regrettable malleability' of TCT constructs. TCT seemed cast as a high level general theory, its uncalibrated constructs permitting empirical data to be fitted to support the theory all too easily. This becomes especially problematic where, as in several IS outsourcing studies we have reviewed, TCT is assumed to be a fully explanatory theory and few tests of its predictiveness in terms of outsourcing success or failure are carried out. This finding also raised the question, not pursued in detail here, whether other non-IT focused empirical studies actually corroborate transaction cost economics, as Williamson suggests, or also raise more questions than they answer. In fact reviews of the limited number of empirical studies are hardly decisive (Joskow, 1991; Shelanski, 1991; Hodgson, 1994), and suggest that at the very least alternative explanatory hypotheses should be considered.

\section{Advances in theory}

Initially the focus is on transaction cost economics because it has become a major starting point for those studying IS outsourcing. Furthermore, many of the papers in this issue touch on TCT and its importance in helping to understand the IS outsourcing phenomenon. We place the paper of Cheon et al. first because it adds to the debate by providing a detailed overview of several alternative theoretical models of outsourcing. While these include resource based theory, resource dependence theory and agency cost theory, the authors also advance the debate even further by putting forward a contingency model for IS outsourcing. They invite further expansion of the model as well as its use as a guide for future empirical research. Clark et al. also show how 'if rational cost-economizing behaviour defines one end of the spectrum, then viewing decision outcomes as the result of power and politics defines the other ... the two perspectives are not however, mutually exclusive'. De Loof's paper also shows how additional theories and frameworks, including coordination theory and material from the competitive strategy and microeconomics literatures, can be usefully employed in the process of setting up a research design for subsequent empirical work on IS outsourcing.
Klepper provides a further theoretical development in looking at how the much discussed notion of 'partnering' between client and vendor company can be conceptualised and delivered. Clark et al. also devote some space to develop their own empricially-based observations in this area of managing the alliance, and suggest that the truly critical success factors associated with successful outsourcing are those relating to vendor governance. Klepper devotes most of his paper to the partnering issue and his highly useful review of partnering studies in the management literature finds that social exchange theory underlies many of the contributions. He then utilizes work by Ring and Van de Ven (1994) and Dwyer et al. (1987) to show how partnerships in IS outsourcing may be studied, but also built and sustained. The development of this work on aspects of partnering in IS outsourcing is critically needed, given the rising number of long term 'total' outsourcing contracts in the 1990s in the developed economies, and the relatively few extant studies that have dealt in detail with partnering specifically in the IS outsourcing context (e.g. see Henderson, 1990; McFarlan and Nolan, 1995; Willcocks, 1995). Following Klepper's lead, there may well be many extant useful theories and frameworks found in alternative, non-IS literatures; the strategic alliance and marketing literatures would seem to be particularly replete with work done on the partnering issue.

Jurison also provides a theoretical paper in working through transaction cost theory assumptions and modern theory of investments and finance to arrive at a decision-making model for IS outsourcing in conditions of risk. In practice Jurison integrates a risk and return model with transaction cost economics, thus enriching the perspective TCT can provide on IS outsourcing. This is important because in all too many evaluations risk is given inadequate attention (Willcocks et al., 1995). Furthermore the model can be used not just to assess outsourcing against in-house options, but also for assessment of competing vendors. Jurison also points out correctly that the risk and return model is not restricted in its applicability to TCT but can also provide a rich framework for analysing decisions from political and agency theory perspectives, and can also be applied to assessing the degree of risk where there are conflicts between client and vendor goals.

\section{Revealing outsourcing practice}

Given the relative immaturity of the IS outsourcing market, and the lack of experience of many client organizations in dealing with IS outsourcing, we still need a continuing flow of empirical evidence, in order to assess the viability of explanatory theoretical frame- 
works, and also as some basis for testing out any prescriptions for good practice. Four papers in this issue add significantly to the complex picture on how IS outsourcing is being practised. Clark et al., carried out 63 in-depth interviews with executives over two years. Their paper focuses on developments in the USA and discusses the nature and size of the market, how decisions are arrived at, and the complex and varied forces driving outsourcing at work - technological, organizational, sectoral and managerial. They also find from their research a variety of reasons for and against outsourcing; or more accurately benefits experienced and risks encountered.

McLellan et al., provide additional empirical material in their in-depth study of seven outsourcing alliances in the US/North American banking industry. In general the outsourcing contracts had been signed in the late $1980 \mathrm{~s}$ for a five to ten year period. In all cases, at least $75 \%$ of the IS budget was outsourced, representing a major organizational change for these firms. Their particular focus is on the financial and strategic motivations behind these outsourcing arrangements. They found financial motivations as a key part of the IS outsourcing decision two financial institutions had disappointing financial performance before outsourcing, and one was experiencing clear financial difficulties - but there were also important strategic motivations that influenced each of the seven decisions. This paper is highly useful as a sectoral-based study that adds to the picture on major long term outsourcing collaborations. It also serves to position the more iconoclastic work recently presented by Strassmann (1995). In analysing companies frequently mentioned in the press for their outsourcing actions he concluded that there was a strong correlation between heavy outsourcing of IT and a company's prior financial position and headcount reduction strategy: 'corporations that outsourced heavily were economic losers heading into the outsourcing act ... the losers were casting off IT because they were already shrinking their firm'. Interestingly, the majority of cases cited by Strassmann refer to contracts signed after 1990, while McLellan et al., studied contracts starting in the 1977-90 period. Their last deal - First Fidelity Bank and EDS, August 1990 - is not mentioned in the Strassmann study.

To further this debate it is worth commenting on our own research findings on 'total' outsourcing successes and failures. We investigated 61 sourcing decisions in USA and Europe; 13 of these were total outsourcing decisions of the sort investigated by McLellan et al., and also Strassmann. Our particular focus was on success and failure. We measured this by comparing outcomes against participant expectations; against 'anticipated cost savings' since cost savings were cited as a major expectation in $85 \%$ of cases - there were clear financial outcomes in 53 out of the sourcing decisions; and against satisfaction factors, for example service levels maintained or better, low levels of dispute, decision to renew contract. In discounting all those deals where the outcome was not clear or it was too early into the contract to tell, of 14 total outsourcing decisions two could be adjudged successful and five unsuccessful. This contrasted remarkably with the selective sourcing record where out of 32 decisions 22 were successful, and only four were unsuccessful (Lacity et al., 1996). Clearly this is becoming a very interesting area of academic study, especially given the drive amongst many vendors and some companies for large-scale outsourcing and long term deals.

De Loof's paper is particularly welcome for providing insight into practice in a European (in this case Dutch) context. It is clear that the US outsourcing market is by far the biggest and most advanced. In Europe the UK represents the biggest and the fastest developing market, with some $£ 1.1$ billion revenue recorded for 1994 , and a double figure growth rate anticipated for 1995 . However there does seem to have been a slow increase in outsourcing across the more developed European economies, particularly in public sector organizations. De Loof carried out an analysis of 23 IS outsourcing arrangements in six mainly public sector organizations. He produces a wealth of detail on the reasons for outsourcing, who made the decisions, the size of outsourcing, how bids were organized, the management of the outsourcing process, and the results organizations were getting.

The other detailed empirical paper in this issue is by Sobol and Apte. Their study of US-based organizations investigates, amongst other issues, what type of companies are more likely to outsource IS, what is being outsourced, what are the reasons advanced for and against outsourcing, who initiates and who makes the final decision. These results help to give more detail to what organizational practices are in the outsourcing arena. The authors also make a new contribution in their examination of domestic versus 'global' (i.e. US firms outsourcing to non-US vendors) outsourcing. 'Global' or offshore outsourcing is very much a developing field but has been the subject of little study so far. While the authors' work is restricted to looking at US firms, their paper does manage to shed a great deal of light on the reasons why organizations may or may not choose to undertake 'global' outsourcing. One interesting finding is that the median cost saving needed for US-based outsourcing emerged as $20 \%$ while for global outsourcing it was $30 \%$ - presumably reflecting the higher risks associated with outsourcing, but also perhaps the predominant driver of global outsourcing, at least in the early 1990s. 


\section{Are there emerging management principles?}

Finally, several of the papers make a real contribution to providing guidelines for how to conduct outsourcing assessments and manage outsourcing arrangements. Our own research work has suggested a range of prescriptions in these two areas. Thus a recent paper provides a number of matrices to enable a sourcing assessment to be carried out through examining the primary business, technical and economic factors emerging from our analysis of case studies and survey responses (Lacity et al., 1995). We have also suggested a range of guidelines on assessment issues and on managing the contract and vendor once the deal has been agreed (see e.g. Lacity and Hirschheim, 1995; Willcocks et al., 1995). We have, of course, not been alone in this (see e.g. only, Buck-Lew, 1992; Loh and Venkatraman, 1992b; McFarlan and Nolan, 1995). As research proceeds so ever new or more detailed guidelines will be seen to emerge. Thus our own most recent research suggests, amongst other things, that selective sourcing is the key to rightsourcing; that senior executives, acting without IT's input make poor outsourcing decisions; that internal IT departments should be allowed to compete with external vendor bids; and that shorter (less than four years) contracts are more successful than longer contracts (Lacity et al., 1996). We would not, of course see this as the end of the research story, especially as the types of outsourcing, what the market can offer, and client maturity are already changing over time. Thus in the present issue we welcome Cronk and Sharp adding to the literature by offering a further strategic framework for the outsourcing decision. They suggest how core competence and segmentation analyses of the IT function can be carried out, including analysis of infrastructure activity and the management of the technology life cycle. Clark et al., provide a number of guidelines for practitioners arising from the research they have conducted, while Cheon et al., provide a usable theoretical framework to guide practice in aspects of decision-making on IS sourcing.

What is clear is that IS outsourcing is of major interest to practitioners. The research and academically based studies represented in this theme issue can be a source of more rigorous, objectively carried out, and thoughtthrough analyses than those generally available in the more popular trade literature and press, and from the marketing departments of interested parties on the supply side. One would be surprised if practitioners did not gain a great deal from reading these papers recognizing, of course, that learning on outsourcing must be a continuous process in what is now a fast moving field.

\section{Conclusion}

These papers make a number of contributions to our understanding of the IS outsourcing phenomenon and several ways forward on its management. One question we are regularly asked is: is IS outsourcing different from outsourcing anything else? Our own research-based answer is: no in many ways, but yes on five counts:

(1) IT evolves rapidly; this surrounds IT sourcing decisions with a high degree of uncertainty.

(2) The underlying economics of IT changes rapidly. Although for example price/performance improvements occur in every industry, in few industries do the underlying economics shift as fast as in IT.

(3) The penetration of IT to all business functions is becoming ubiquitous: unlike many other products and services IT cannot be easily isolated from other organizational functions.

(4) The switching costs to alternative information technologies and IT suppliers are high, and sometimes prohibitive.

(5) Many potential and actual customers are still highly inexperienced in IT outsourcing. This can put them at a significant disadvantage when negotiating and running contracts with outsourcing vendors.

Except possibly for the fifth item it is doubtful whether these distinctive characteristics of IT/IS will recede in the next five years, and indeed it is likely that several, especially items one, two and three, will heighten in that period of time. They all serve to render questions relating to sourcing IT/IS capability highly problematic. If the present papers we have collected together serve to illustrate this, they also demonstrate why the IS outsourcing phenomenon is worthy of distinctive study. If they also represent some further advances in theory and practice, we will have done our own bit toward chasing and getting closer to that outsourcing hare bounding off into the distance.

\section{References}

Applegate, L. and Montealegre, R. (1991) Eastman Kodak Company: managing information systems through strategic alliances. (Harvard Business School Case 9-192-030: Boston, MA).

Beath, C. (1983) Strategies for managing MIS projects: a transaction costs approach. Proceedings of the Fourth International Conference on Information Systems, December, pp. 133-47.

Bensaou, M. (1993) Interorganizational cooperation: the role of information technology - an empirical comparison of US and Japanese supplier relations. Proceedings of the 
Fourteenth International Conference of Information Systems, Orlando, FL, December, pp. 117-27.

Brown, B. and Eckerson, W. (1990) Kodak turns nets over to IBM and DEC; farming out net operations can trigger staffing issues. Network World, 7(3), 1, 4, 61, 63.

Buck-Lew, M. (1992) To outsource or not? International Fournal of Information Management, 12, 3-20.

Dwyer, F., Schurr, P. and Oh, S. (1987) Developing buyerseller relationships. Fournal of Marketing, 51, 11-27.

Feeny, D. and Ives, B. (1989) In search of sustainability reaping long term advantage from investments in information technology. Fournal of Management Information Systems, 7 (1), 27-46.

Ganz, J. (1994) Outsourcing: the scam may be on you. ComputerWorld, 18 April, 41.

Harrar, G. (1993) Outsource tales, Forbes, 7 June, 37-42.

Henderson, J. (1990) Plugging into strategic partnerships: the critical IS connection, Sloan Management Review, Spring 7-18.

Hodgson, G. (1994) Corporate culture and evolving competences: an old institutionalist perspective on the nature of the firm. Paper presented at The Conference of Transaction Cost Economics and Beyond, Erasmus University, Rotterdam, Netherlands.

Hopper, M. (1990) Rattling SABRE - new ways to compete on information. Harvard Business Review 68(3), 118-25.

Hovey, V. (1991) Presentation to the University of Huston's Information Systems Research Center, 22 January.

Huber, R. (1993) How Continental Bank outsourced its 'Crown Jewels'. Harvard Business Review 71(1), 121-9.

Ives, B. and Learmouth, J. (1984) The information system as a competitive weapon. Communications of the ACM 27(12), 1193-201

Joskow, P. (1991) The role of transaction cost economics in antitrust and public utility regualtory policies fournal of Law Economics and Organization, 7, 53-83.

Klepper, R. (1993) Efficient outsourcing relationships. Paper at the Outsourcing of Information Systems Services Conference, University of Twente, the Netherlands, 20-22 May.

Lacity, M. and Hirschheim, R. (1993) Information Systems Outsourcing: Myths, Metaphors, and Realities (Wiley, Chichester).

Lacity, M. and Hirschheim, R. (1995) Beyond The Information Systems Outsourcing Bandwagon (Wiley, Chichester).

Lacity, M. and Willcocks, L. (1995) IS outsourcing: assessing a transaction cost interpretation of empirical evidence. Oxford Institute of Information Management Research and Discussion Paper (Templeton College, Oxford).

Lacity, M., Willcocks, L. and Feeny, D. (1995) IT outsourcing: maximize flexibility and control. Harvard Business Review, 84-93.

Lacity, M., Willcocks, L. and Fitzgerald, G. (1996) An empirical investigation of IT sourcing decisions: lessons for best practice. Oxford Institute of Information Management Research and Discussion Paper (Templeton College, Oxford) (forthcoming).

Loh, L. and Venkatraman, N. (1992a) Diffusion of information technology outsourcing: influence sources and the Kodak effect. Information Systems Research 334358.

Loh, L. and Venkatraman, N. (1992b) Determinants of information technology outsourcing: a cross-sectional analysis. Fournal of Management Information Systems, 9, 7-24.

McFarlan, W. F. (1984) Information technology changes the way you compete. Harvard Business Review, 62(3), 98103.

McFarlan, W. and Nolan, R. (1995) How to manage an IT outsourcing alliance. Sloan Management Review, 36(2), 9-24.

Melymuka, K. (1994) Is there life after outsourcing? ComputerWorld, 16 May, 89-96.

Moad, J. (1993) Inside an outsourcing deal. Datamation, 15 February, 20-7

Porter, M. E. and Millar, V. (1985) How information gives you competitive advantage. Harvard Business Review, 63(4), 149-60.

Ring, P. and Van de Ven, A. (1994) Development processes of cooperative relationships. Academy of Management Review, 19(1), 90-118.

Shelanski, H. (1991) Empirical research in transaction cost economics: a survey and assessment (Department of Economics, University of California, Berkeley) December.

Strassmann, P. (1995) Outsourcing - a game for losers. ComputerWorld, 21 August, 75.

Willcocks, L. (1995) Collaborating to compete: strategic partnerships in IT outsourcing? Oxford Institute of Information Management Research and Discussion Paper (Templeton College, Oxford).

Willcocks, L. and Fitzgerald, G. (1994) A Business Guide to Outsourcing IT. A Study of European Best Practice in the Selection, Management and Use of External IT Services (Business Intelligence, London).

Willcocks, L., Lacity, M. and Fitzgerald, G. (1995) IT outsourcing in Europe and the USA: assessment issues. In: Proceedings of the Third European Conference In Information Systems, Athens, 1-3 June.

Williamson, O. (1975) Markets and Hierarchies: Analysis and Antitrust Implications, A Study in the Economics of Internal Organization (The Free Press, New York).

Williamson, O. (1979) Transaction cost economics: the governance of contractual relations. Fournal of Law and Economics, 22(2), 233-61.

Williamson, O. (1985) The Economic Institutions of Capitalism (The Free Press, New York). 